\title{
Registry of Transthyretin Amyloidosis in the State of São Paulo (REACT-SP)
}

\author{
Fabio Fernandes, ${ }^{1}$ Caio Cafezeiro, ${ }^{1}$ Renata Margarida do Val, ${ }^{1}$ Alexandra Patrícia Zilli Vieira, ${ }^{1}$ Wilson Marques, ${ }^{2}$ \\ Edileide Barros Correia, ${ }^{3}$ Alzira Alves Siqueira Carvalho, ${ }^{4}$ Antonio Carlos Palandrini Chagas, ${ }^{4}$ Acary Souza Bulle \\ Oliveira, ${ }^{5}$ Paulo Victor Sgobi de Souza, ${ }^{5}$ Wladimir Bocca Vieira de Resende Pinto, ${ }^{5}$ Ariane Vieira Scarlatelli \\ Macedo, ${ }^{6}$ Murillo Oliveira Antunes, ${ }^{7}$ Pedro Vellosa Schwartzmann, ${ }^{8}$ Sandrigo Mangini, ${ }^{9}$ Marcus Vinicius Simões ${ }^{2}$ \\ Instituto do Coração-HC FMUSP, ${ }^{1}$ São Paulo, SP - Brazil \\ Hospital das Clínicas da Faculdade de Medicina de Ribeirão Preto da Universidade de São Paulo, ${ }^{2}$ São Paulo, SP - Brazil \\ Instituto Dante Pazzanese de Cardiologia, ${ }^{3}$ São Paulo, SP - Brazil \\ Centro Universitário de Saúde $A B C,{ }^{4}$ São Paulo, SP - Brazil \\ Associação Paulista para o Desenvolvimento da Medicina Hospital São Paulo, ${ }^{5}$ São Paulo, SP - Brazil \\ Instituto de Pesquisa e Inovação Tecnológica da Santa Casa de São Paulo, ${ }^{6}$ São Paulo, SP - Brazil \\ Hospital Universitário São Francisco na Providência de Deus, ${ }^{7}$ Bragança Paulista, SP - Brazil \\ Clinicor Clínica Cardiológica, ${ }^{8}$ Ribeirão Preto, SP - Brazil \\ Hospital Israelita Albert Einstein, ${ }^{9}$ São Paulo, SP - Brazil
}

\begin{abstract}
Background: Amyloidosis is a systemic disease that involves multiple organs, characterized by the deposition of amyloid fibrils. Knowledge regarding the epidemiological, clinical, and genetic profile of the population affected by amyloidosis throughout the country is of fundamental importance for establishing diagnostic and therapeutic strategies.

Objective: To evaluate the epidemiological, clinical, laboratory, imaging, and treatment variables of patients with TTR cardiac amyloidosis.

Methods: A multicenter, retrospective, prospective, and observational study based on collection of data on the natural history of patients with TTR amyloidosis, followed in the state of São Paulo.

Results: To make it possible to map the regional distribution of the disease, increasing knowledge about the disease among clinicians and specialists in different areas. To evaluate patients with hereditary and wild-type TTR amyloidosis, in addition to following individuals with positive genotype and negative phenotype.

Conclusion: The information collected may show greater awareness of the disease, development of new diagnostic and treatment flowcharts with a direct impact on knowledge of the natural history of the disease and patient prognosis.
\end{abstract}

Keywords: Amyloidosis; Ventricular Hypertrophy; Heart Failure.

\section{Introduction}

Amyloidosis is characterized by the deposition of amyloid fibrils in the extracellular space of several organs, such as the heart, peripheral nerves, and gastrointestinal tract. ${ }^{1,2}$ The 2 most common types of amyloidosis are those caused by monoclonal proteins (AL) and those caused by hepatic transthyretin (TTR) proteins. The TTR form can be further divided into 2 types: hereditary, when there is a known

Mailing Address: Fábio Fernandes •

Cardiomyopathies Group. Av Dr Enéas de Carvalho Aguiar, 44.

Postal Code: 05403-000, Cerqueira César, SP - Brazil.

E-mail: fabio.fernandes@incor.usp.br

Manuscript received September 20, 2021, revised manuscript October 04, 2021, accepted October 04, 2021

DOI: https://doi.org/10.36660/abchf.20210028 genetic mutation that causes the disease (ATTRh) and the wild type (ATTRwt, previously known as senile amyloidosis). ${ }^{3}$

TTR protein disorders cause it to dissociate into monomers, which aggregate to form amyloid fibrils and infiltrate the extracellular matrix. The consequences in the heart are increased ventricular wall thickness and myocardial stiffness, in addition to valvular and interatrial septum thickening. Patients present a phenotype of hypertrophic cardiomyopathy, evolving to restrictive cardiomyopathy associated with heart failure syndrome, with poor prognosis. ${ }^{4}$

Mutations related to TTR amyloidosis may be associated with specific phenotypes, with a tendency toward cardiac or neurological involvement, for example. ${ }^{5}$ However, several other factors may also influence phenotype and prognosis, including age, sex, environmental factors, and maternal genetics. ${ }^{6}$ Amyloid heart disease is commonly associated with 
the Val122lle mutation, whereas familial TTR amyloidotic polyneuropathy is more related to the Val30Met mutation

ATTR amyloidosis was considered a rare cause of heart failure, but it was perhaps only underdiagnosed. Technetium bone scintigraphy as a diagnostic technique, associated with advances in therapeutic possibilities, has led to changes in the disease prevalence. $^{7,8}$ The nonspecific symptomatology of this disease and its heterogeneous phenotype make this a challenging task, but identifying patients at an early stage is essential for the use of disease-modifying medications and a better opportunity to impact patients' clinical course.

It could be extremely useful to know the epidemiological, clinical, and genetic profile of the population affected by amyloidosis in the state of São Paulo, as well as patients' age and time to diagnosis, exams conducted, medical specialty consulted, evolution of the clinical condition, and the treatment used. This information is lacking in Brazil, and it may make it possible to adopt public policies in order to raise awareness of the disease, target investments, and create new diagnosis and treatment flowcharts with a direct impact on knowledge of the disease's natural history and patients' prognosis.

\section{Objectives}

\section{Primary}

To describe the population affected by TTR-associated amyloidosis, evaluating the epidemiological and clinical variables, complementary laboratory and imaging methods, and treatment types of patients in the state of São Paulo.

\section{Methods}

\section{Study design and population}

This is a multicenter, retrospective, prospective, and observational study. It will include patients of both sexes, with a minimum age of 18 years, who are followed for TTR-associated amyloidosis, including both the hereditary and wild-type disease, including polyneuropathy and cardiomyopathy, as well as participants with TTR mutations who have not been diagnosed with ATTR, in the state of Sao Paulo.

Data will be collected from patients' medical records at the service of origin, after the last follow-up visit, and data collection must be carried out using the online platform (REDCap). Data from all patient consultations will be recorded and entered into the data registry/electronic database. This study will include an estimated 600 patients.

The following research centers will participate: Instituto do Coração-HC FMUSP, Instituto Dante Pazzanese de Cardiologia, Hospital das Clínicas da Faculdade de Medicina de Ribeirão Preto da Universidade de São Paulo, Centro Universitário de Saúde ABC, Associação Paulista para o Desenvolvimento da Medicina Hospital São Paulo, Instituto de Pesquisa e Inovação Tecnológica da Santa Casa de São Paulo, Hospital Universitário São Francisco na Providência de Deus, Clinicor Clínica Cardiológica, and Hospital Israelita Albert Einstein. Centers with volumes of patients with forms of ATTR may be selected. New centers may be included, if they include at least 10 patients with ATTR.

In order to participate in REACT, each research unit must obtain approval from the local Research Ethics Committee before beginning to enroll patients. The study will only be conducted in units where approval has been obtained from the Research Ethics Committee. It is the responsibility of investigators to obtain future approval of the study protocol.

Patients will be enrolled in the study based on the results of genotyping, which will be conducted prior to the last visit, in accordance with the units' standard practices. TTR genotyping is required to confirm patient eligibility. For patients with a documented TTR mutation, the mutation(s) will be entered into the their medical records.

All tests necessary to confirm diagnosis of ATTR will be conducted prior to the last visit.

\section{Inclusion criteria}

\section{- Patients and disease characteristics}

1. Male or female sex $\geq 18$ years.

2. TTR mutation confirmed by genotyping, with or without diagnosis of ATTR or wild-type TTR amyloidosis. Confirmation of wild-type TTR amyloidosis will be determined by genotyping, confirming that the patient does not have a known mutation in the TTR gene (i.e., only a carrier of the wild-type allele), by means of genetic testing and one of the following criteria (A, B or $\mathrm{C}$ ):

a. Evidence of cardiac involvement on echocardiography, as defined by mean left ventricular wall thickness $>12 \mathrm{~mm}$ and presence of amyloids in cardiac tissue on biopsy confirmed as TTR amyloid by mass spectrometry or immunohistochemistry; or

b. Evidence of cardiac involvement on echocardiography, as defined by mean left ventricular wall thickness $>12$ $\mathrm{mm}$ and presence of amyloids in non-cardiac tissue on biopsy confirmed as TTR amyloid by mass spectrometry or immunohistochemistry; or

c. Evidence of cardiac involvement on echocardiography, as defined by mean left ventricular wall thickness $>12 \mathrm{~mm}$, without evidence of primary (light chain) amyloidosis and presence of amyloid in cardiac tissue, indirectly confirmed by scintigraphy with a bone tracer, for example, $99 \mathrm{mTC}$ DPD (99mTC-3,3-diphosphono-1,2-propane-dicarboxylic acid), 99mTC-PYP (pyrophosphate), or 99mTC-HMDP (hydroxymethylene diphosphonate), with Perugini grade $\geq 2$.

\section{Exclusion criteria}

- Patients with primary or secondary amyloidosis.

\section{Statistical analysis}

Analysis of clinical outcomes will be performed for all enrolled patients whose data are available. Results will be examined for the entire patient group, as well as by stratifying important variables that may affect outcomes (including, but not limited to TTR variant, age, race, gender, country of origin, and transplant recipient status). 
Data for continuous variables will be presented as statistics of position and scale (mean and standard deviation and/or median and interquartile range). Categorical variables will be presented as absolute and relative frequencies. Comparisons between cohorts and subgroups will be made using the chi-square test for categorical variables. Student's t test will be used for paired and unpaired comparisons, when appropriate. Nonparametric tests (Wilcoxon rank-sum test) will be used when data are not normally distributed.

\section{Limitations to the research methods}

The observational nature of this study may potentially introduce selection or verification bias. The study population could be more heterogeneous. Confounding factors lead to biased estimates of associations of risk factors or treatments with the result and, therefore, affect the validity of study conclusions. Analytical methods (such as multivariate, corresponding regression) should be used to control for the occurrence of confounding factors. Other potential limitations to study validity include missing data.

\section{Chronogram of the Project}

\begin{tabular}{lc}
\hline Step & Planned date \\
\hline $\begin{array}{l}\text { Beginning of data collection (first } \\
\text { subject first visit [FSFV]) }\end{array}$ & 15 October 2021 \\
\hline $\begin{array}{l}\text { End of data collection (last subject } \\
\text { last visit [LSLV]) }\end{array}$ & 15 December 2022 \\
\hline Study progress reports & $\begin{array}{c}\text { Study progress reports should be } \\
\text { sent in May 2022 }\end{array}$ \\
\hline Final study report & 23 December 2022 \\
\hline
\end{tabular}

\section{Author contributions}

Conception and design of the research: Fernandes $F$, Cafezeiro C, Val RM, Vieira APZ, Marques W, Correia EB, Carvalho AAS, Chagas ACP, Oliveira ASB, Souza PVS, Pinto WBVR, Macedo AVS, Antunes MO, Schwartzmann PV, Mangini S, Simões MV. Acquisition of data: Fernandes

\section{References}

1. Hawkins PN, Ando Y, Dispenzeri A, Gonzalez-Duarte A, Adams D, Suhr OB. Evolving Landscape in the Management of Transthyretin Amyloidosis. Ann Med. 2015;47(8):625-38. doi: 10.3109/07853890.2015.1068949.

2. Ruberg FL, Berk JL. Transthyretin (TTR) Cardiac Amyloidosis. Circulation. 2012;126(10):1286-300. doi: 10.1161/CIRCULATIONAHA.111.078915.

3. Buxbaum JN, Tagoe CE. The Genetics of the Amyloidoses. Annu Rev Med. 2000;51:543-69. doi: 10.1146/annurev.med.51.1.543.

4. Elliott $\mathrm{P}$, Andersson B, Arbustini E, Bilinska Z, Cecchi F, Charron P, et al. Classification of the Cardiomyopathies: A Position Statement From the European Society Of Cardiology Working Group on Myocardial and Pericardial Diseases. Eur Heart J. 2008;29(2):270-6. doi: 10.1093/eurheartj/ehm342.

5. Carr AS, Pelayo-Negro AL, Evans MR, Laurà M, Blake J, Stancanelli C, et al. A Study of the Neuropathy Associated With Transthyretin Amyloidosis (ATTR)
F, Cafezeiro C, Val RM, Vieira APZ, Marques W, Correia EB, Carvalho AAS, Chagas ACP, Oliveira ASB, Souza PVS, Pinto WBVR, Macedo AVS, Antunes MO, Schwartzmann PV, Mangini S, Simões MV. Analysis and interpretation of the data: Fernandes F, Cafezeiro C, Val RM, Vieira APZ, Marques W, Correia EB, Carvalho AAS, Chagas ACP, Oliveira ASB, Souza PVS, Pinto WBVR, Macedo AVS, Antunes MO, Schwartzmann PV, Mangini S, Simões MV. Statistical analysis: Fernandes F, Cafezeiro C, Val RM, Vieira APZ, Marques W, Correia EB, Carvalho AAS, Chagas ACP, Oliveira ASB, Souza PVS, Pinto WBVR, Macedo AVS, Antunes MO, Schwartzmann PV, Mangini S, Simões MV. Obtaining financing: Fernandes F, Val RM. Writing of the manuscript: Fernandes F, Simões MV, Cafezeiro C, Vieira APZ. Critical revision of the manuscript for intellectual content: Fernandes F, Cafezeiro C, Val RM, Vieira APZ, Marques W, Correia EB, Carvalho AAS, Chagas ACP, Oliveira ASB, Souza PVS, Pinto WBVR, Macedo AVS, Antunes MO, Schwartzmann PV, Mangini S, Simões MV. Supervision / as the major investigador: Fernandes F, Cafezeiro C, Val RM, Vieira APZ, Marques W, Correia EB, Carvalho AAS, Chagas ACP, Oliveira ASB, Souza PVS, Pinto WBVR, Macedo AVS, Antunes MO, Schwartzmann PV, Mangini S, Simões MV.

\section{Potential Conflict of Interest}

No potential conflict of interest relevant to this article was reported.

\section{Sources of Funding}

This study was funded by Grant Phizer 68322757.

\section{Study Association}

This study is not associated with any thesis or dissertation work.

\section{Ethics approval and consent to participate}

This article does not contain any studies with human participants or animals performed by any of the authors. in the UK. J Neurol Neurosurg Psychiatry. 2016;87(6):620-7. doi: 10.1136/ jnnp-2015-310907.

6. Rapezzi C, Quarta CC, Riva L, Longhi S, Gallelli I, Lorenzini M, et al Transthyretin-Related Amyloidoses and the Heart: A Clinical Overview. Nat Rev Cardiol. 2010;7(7):398-408. doi: 10.1038/nrcardio.2010.67.

7. Gillmore JD, Maurer MS, Falk RH, Merlini G, Damy T, Dispenzieri A, et al Nonbiopsy Diagnosis of Cardiac Transthyretin Amyloidosis. Circulation. 2016;133(24):2404-12. doi: 10.1161/CIRCULATIONAHA.116.021612.

8. Benson MD, Waddington-Cruz M, Berk JL, Polydefkis M, Dyck PJ, Wang AK, et al. Inotersen Treatment for Patients with Hereditary Transthyretin Amyloidosis. N Engl J Med. 2018;379(1):22-31. doi: 10.1056/ NEJMoa1716793. 
